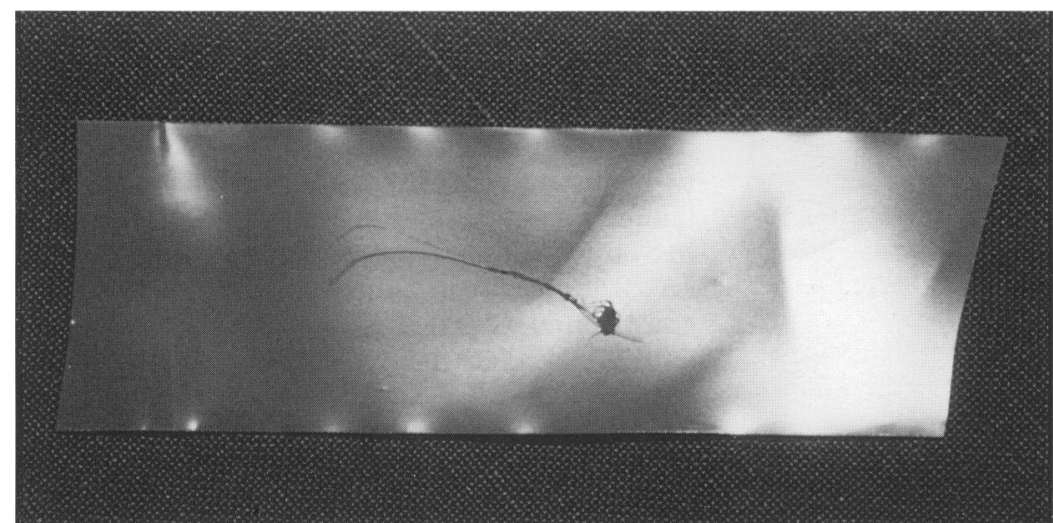

Figure 3 The hair tourniquet. Note the multiplicity of strands.

and 3) and Z-plasty fashioned over the dorsal skin in anticipation of constrictive scarring (fig 4). The toe healed uneventfully.

\section{CASE 2}

A three month old boy was referred with a two day history of irritability and swollen right second toe. A subcutaneous hair thread tourniquet was found and removed. Congestion subsided over the next few days. The toe healed well with conservative wound care.

\section{Discussion}

There have been 67 previous reports of "hair thread tourniquet syndrome" involving fingers, toes, and the external genitalia. ${ }^{12}$ The mechanism of injury is the impairment of lymphatic drainage by the constricting hair or thread. Strangulation becomes established with obstruction to the venous outflow and the arterial inflow. The tourniquet of hair or thread eventually cuts through the oedematous skin and becomes embedded deep in the subcutaneous tissue. Skin epithelialisation can occur to completely bury the tourniquet. The swollen, discoloured and cool appendage eventually undergoes necrosis and may autoamputate.

Prompt and complete removal of all constricting material is essential. Surgical exploration must be considered mandatory if doubt

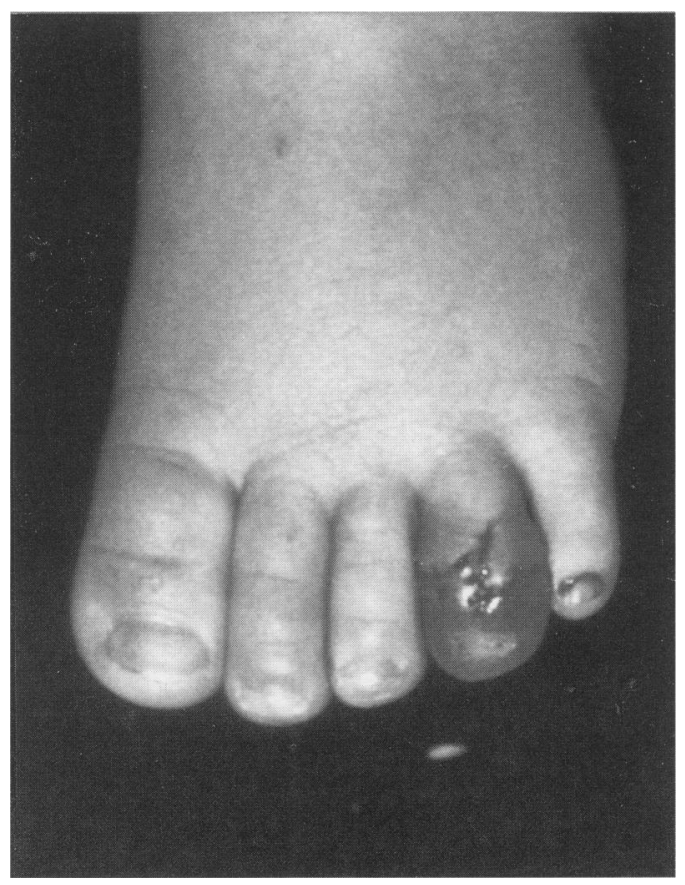

Figure 4 The toe following removal of the hair tourniquet. $A$ dorsal Z-plasty was fashioned. Note reactive hyperaemia.

persists as to the completeness of the removal, especially as the constricting hair cuts through the skin and becomes invisible.

Reported complications of digital tourniquets include tissue loss, flexion deformities, and amputations. Higher rates of complication were found in external genitalia strangulations and these include urethrocutaneous fistulae and gangrene of the glans. ${ }^{1}$

In all cases the possibility of non-accidental injury should be borne in mind, although most appear to have been inadvertent. One piece jump suits and mittens with loose nylon threads have been identified as sources of the ligatures. ${ }^{2}$

1 Barton DJ, Sloan GM, Nichter LS, Reinisch JF. Hair-thread tourniquet syndrome. Pediatrics 1988;82:925-8.

2 Collins AG. Hair-thread tourniquet syndrome [letter]. Aust f Dermatol 1990;31:117-8.

\title{
Weever fish stings: a report of two cases presenting to an accident and emergency department
}

\author{
R S Davies, R J Evans
}

Welsh National

Poisons Unit,

Ward West 5 ,

Llandough Hospital,

Cardiff CF64 2XX

R J Evans

Correspondence to: Dr R J Evans,

Accident and Emergency Department,

Cardiff Royal Infirmary,

Newport Road,

Cardiff CF2 1SZ

\author{
Abstract \\ Two patients are described who suffered \\ weever fish stings and presented to an \\ accident and emergency department. The \\ characteristic symptoms and treatment \\ are described. \\ ( $\mathcal{F}$ Accid Emerg Med 1996;13:139-141)
}

Key terms: weever fish; fish venom; bites and stings; poisonous fish

Weever fish are among the most venomous fish present in the temperate zone. They are found in European coastal waters (Baltic to North Africa), the eastern Atlantic Ocean, and 


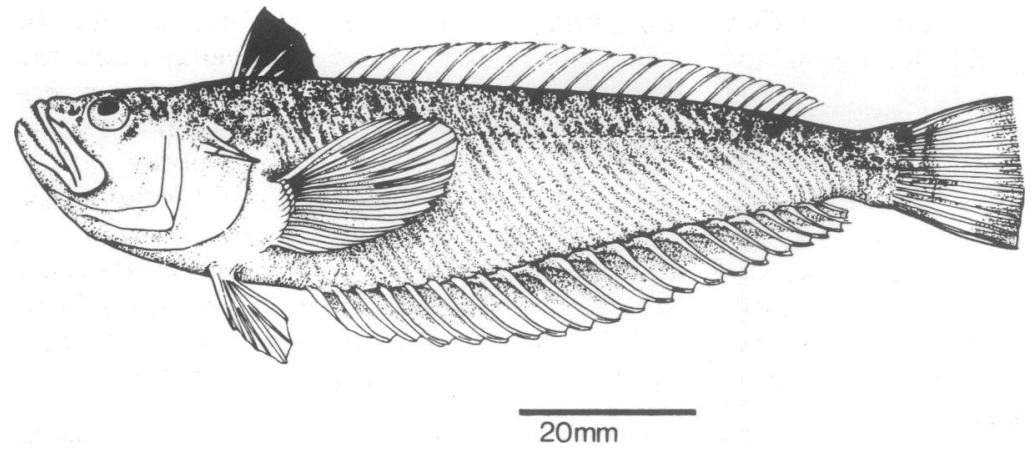

the Mediterranean Sea. ${ }^{1}$ The weever fish is a short, stout fish ranging in length from $14 \mathrm{~cm}$ (lesser weever fish, Echiichthys vipera) to $46 \mathrm{~cm}$ (greater weever fish, Trachinus draco). The lesser weever fish inhabits shallow inshore waters where the bottom is flat or sandy and muddy. The greater weever fish lives in deeper, offshore waters (to a depth of $30 \mathrm{~m}$ ) and is the species usually responsible for the stings suffered by fishermen and divers. Both species spend much of the day partly buried in the sand or mud, with only the head and back exposed. ${ }^{2}$ The fish are usually a yellow-grey colour, with a whitish underside, and have eyes that are located almost on top of a flat head. ${ }^{3}$ The fish possess approximately six venomcontaining spines in the front dorsal fin and a single spine on each main gill cover (figure).

Within the dorsal spines are two grooves composed of holocrine glandular tissue. The spines are covered with a thin integument of stratified columnar epithelium that ruptures during contact with the victim and thus releases the venom. The venom, an ichthyoacanthotoxin, contains several thermolabile proteins, including 5-hydroxytryptamine, a kinin or kinin-like substance, adrenaline, noradrenaline, histamine, possibly serotonin as well as several enzymes. ${ }^{4}$ The venom causes wheal and flare reactions in subcutaneous injections and is lethal to some animals. ${ }^{4}$ Recently a major toxic component of the greater weever fish called dracotoxin, with membrane depolarising and haemolytic properties, has been isolated from the crude venom. ${ }^{5}$

In summer, the fish prefers shallow water where it buries itself in the mud or sand with eyes, mouth and dorsal fin protruding above the surface where it awaits prey such as crabs or shrimps. ${ }^{1}$ Fishermen can sustain an injury while handling fish caught in nets. ${ }^{4}$ However, the most common injury is to the lower extremities when bathers tread on partially submerged dorsal spines. ${ }^{6}$ Occasionally the fish may lunge at a bather, when the gill cover spines alone are employed. ${ }^{1}$ In France the weever fish is considered a delicacy and is sold commercially; since the venom remains potent for several hours, care must be taken when handling the fish.

We report two cases of weever fish stings which presented to an accident an emergency (A\&E) department.

\section{Case reports}

CASE 1

A 16 year old girl presented to the $A \& E$ department after sustaining a weever fish sting to her right hand. She was working with the launch crew of a life boat on a stretch of beach in South Wales in August. She placed her hand on the sandy shore and immediately complained of severe pain to the puncture site which extended from the digit to the whole hand. The patient was given an antihistamine by the lifeboat doctor at the scene and when she saw her general practitioner the next morning she was prescribed erythromycin. Later that day she presented to the $A \& E$ department, were she was found to have a swollen erythematous right hand and forearm. She was prescribed an analgesic (dihydrocodeine tartrate) for pain relief, and the arm was elevated with a sling. On review the next morning the hand was still swollen and the patient was advised to continue with elevation, antibiotics, antihistamines, and analgesics (ibuprofen). Telephone follow up revealed that the pain and swelling settled completely after five days.

CASE 2

A 48 year old woman presented to our $A \& E$ department seven days after sustaining a weever fish sting when wading out to sea while on holiday in Portugal. She immediately complained of excruciating pain which she described as "a twisting knife", after which the foot became swollen and red. The local beach attendant felt it important to squeeze the venom from the wound and to make it bleed. He then sprayed an unknown cold substance on the foot but this made the pain much worse. After a couple of hours the severe pain subsided but an irritation persisted, especially on weight bearing. On examination the wound, although tender to palpation, had healed well, so the patient was reassured and discharged. Telephone follow up revealed that the foot irritation and mild discomfort on weight bearing persisted for three weeks.

\section{Discussion}

Systemic symptoms after weever fish stings are probably overstated, and reported fatalities that occur follow stings of the greater weever fish and are more consistent with secondary sepsis than venom effects. ${ }^{7}$ There are no recent reports of serious cases. Immediately after envenomation the patient develops intense pain at the puncture site, which may be excruciating and difficult to control with analgesics. There is an account dating from 1782 of a fisherman who amputated his finger to relieve pain caused by the greater weever fish. ${ }^{7}$

The pain can increase in severity over an hour and lasts for up to 24 hours. ${ }^{1}$ The pain is usually localised around the site of penetration but may affect the whole foot or hand and even the whole limb. The limb may feel numb, with associated erythema and oedema which may extend proximally from the wound over the next few hours. Inflammation of 
the wound may continue for up to 14 days and movement of the limb can be greatly restricted. ${ }^{2}$

A broad array of systemic symptoms may accompany envenomation. The victim may be agitated, pale, or anxious and headaches, nausea, vomiting, sweating, and syncope may occur rarely. There is a case report of a six week pregnant woman who developed vaginal bleeding immediately after a weever fish envenomation and three weeks later spontaneously aborted the fetus. ${ }^{8}$

Management of a weever fish sting should be to immerse the affected limb or wound promptly in hot water (approximately $40^{\circ} \mathrm{C}$ or as hot as can be tolerated) for about 20 minutes, though care should be taken to avoid scalding. If immersion is not possible, hot soaks or a poultice should be applied. ${ }^{7}$ This will dramatically ease the pain within a few minutes, as the toxin is thermolabile. Cold application worsens the pain. ${ }^{9}$ Usually, simple analgesics will relieve residual pain but on occasions opiate analgesia may be required. Injection of local anaesthetic, either by infiltration or by regional nerve block, may also be considered. Intravenous calcium gluconate has been found to be effective in relieving pain in a case where intravenous narcotics failed. ${ }^{10}$ Local wound toilet, debridement, and tetanus prophylaxis are provided as necessary. The spines only rarely embed in the tissue. ${ }^{27}$
Infection is rare but antibiotics will be necessary if local infection develops, and can be considered for prophylaxis in the immunocompromised patient. Antihistamines may relieve the local inflammatory response. Otherwise treatment is supportive. Occasionally, envenomation will be accompanied by an allergic reaction and treatment for anaphylaxis will be necessary. ${ }^{10}$ Prevention is primarily by avoidance, wearing sufficient protective footwear, and never handling weever fish. ${ }^{11}$

I wish to thank $\mathrm{Mr}$ Gordon Howes for his advice and his drawing of the lesser weever fish.

1 Cain D. Weever fish sting: an unusual problem. $B M \mathcal{F}$ $1983 ; 287: 406-7$

The stinging Weever fishes. Practitioner

1975;215:223-5.
3 Gonzaga RAF. Venomous fish stings on the European seashore. Postgrad Med 1985;77:146-8.

4 Ellenhorn MJ, Barceloux DG Medical toxicology: diagnosis and treatment of human poisoning 1st ed Amsterdam:

5 Chhatwal I, Dreyer F. Isolation and characterization of dracotoxin from the venom of the Greater Weever fish Trachinus draco. Toxicon 1992:30:87-93.

6 Viccellio P. Handbook of medical toxicology, 1st ed. Boston: Little, Brown, 1993.

7 Briars GL, Gordon GS. Envenomation by the Lesser Weever fish. Br $\mathcal{F}$ Gen Pract 1992;42:213.

8 Gonzago RAF. Spontaneous abortion after a Weever fish

sting. $B M \mathcal{F} 1985 ; 290: 518$.
9 Russell $\mathrm{FE}$. Weever fish sting: the last word. $B M \mathcal{F} 1983$; 287:981-2.

10 McGoldrick J, Marx JA. Marine envenomations. Part 1. Vertebrates. F Emerg Med 1990;9:497-502.

11 Brown CK, Shepherd SM. Marine trauma, envenomations and intoxications. Emerg Med Clin North Am 1992;10: 385-408.

\title{
Lumps, bumps and soft tissue sarcomas
}

\author{
Sean J McGovern
}

\begin{abstract}
A case of soft tissue sarcoma in a young person is described. Accident and emergency workers should be aware of this highly malignant group of tumours. Lumps in young people should not necessarily be assumed to be benign without a definite histological diagnosis.
\end{abstract}

(f Accid Emerg Med 1996;13:141-142)

Key terms: soft tissue sarcoma; diagnosis

Soft tissue sarcomas are a diverse group of uncommon neoplasms representing less than $1 \%$ of cancer admissions to hospital. ${ }^{1}$ The prevalence of these tumours in Ireland is thought to be similar to that in North America, that is, 2 per 100000 of population. ${ }^{2}{ }^{3}$ There have been reports of an increase in these tumours in a number of western countries; however, preliminary evidence suggests that this increase may be due to the increase in Kaposi's sarcoma in AIDS patients. ${ }^{45}$ Those who work in primary care or in accident and emergency medicine need to consider these uncommon tumours in the differential diagnosis of any soft tissue mass, as they are highly malignant and can simulate a benign process, especially in the young.

\section{Case report}

$\mathrm{KW}$, an 18 year old Chinese student, attended an accident and emergency (A\&E) department complaining of a painless $2 \mathrm{~cm} \times 2 \mathrm{~cm}$ lump on the medial aspect of his left thigh for three weeks. The patient was reassured that it was a benign lump. Seven months later he presented to another $\mathrm{A} \& \mathrm{E}$ department complaining of a marked increase in size of the lump over the previous few days, associated with pain. On examination there was a $14 \mathrm{~cm} \times 6 \mathrm{~cm}$ swelling on the medial aspect of his left thigh. It was tender to touch and fixed to the muscle with overlying skin changes. The patient was going to Hong Kong for two months and he refused admission. He was advised to seek urgent medical attention while in Hong Kong.

On return two months later he attended surgical outpatients. He was noted to have an $18 \mathrm{~cm} \times 6.5 \mathrm{~cm}$ hard craggy mass on the 